\title{
A EDUCAÇÃO EM ESPAÇOS DE RESTRIÇÃO E PRIVAÇÃ̂O DE LIBERDADE NO BRASIL PERSPECTIVAS E CONCEPÇÕES
}

\author{
EDUCATION IN RESTRICTED AREAS AND FREEDOM OF LOSS IN BRAZIL: \\ PERSPECTIVES AND CONCEPTS
}

LA EDUCACIÓN EN ESPACIOS DE RESTRICCIÓN Y PRIVACIÓN DE LA LIBERTAD EN BRASIL: PERSPECTIVAS Y CONCEPCIONES

Elionaldo Fernandes Julião*

Doutor em Ciências Sociais - UERJ | Brasil E-mail: elionaldoj@yahoo.com.br

\begin{abstract}
REVISTA PEDAGÓGICA
Revista do Programa de Pós-graduação em Educação da Unochapecó | ISSN 1984-1566 Universidade Comunitária da Região de Chapecó | Chapecó-SC, Brasil Como referenciar este artigo: JULIÃO. Elionaldo Fernandes. A educação em espaços de restrição e privação de liberdade no Brasil: perspectivas e concepções. Revista Pedagógica, Chapecó, v.16, n.32, p. 191-206, jan./jul. 2014.
\end{abstract}

\begin{abstract}
RESUMO:Fruto das pesquisas desenvolvidas nos últimos anos sobre a educação para jovens e adultos em situação de restrição e privação de liberdade no Brasil, o artigo procura apresentar algumas reflexões sobre o tema, destacando, principalmente, os aspectos legais, políticos e sociais que envolvem a discussão. Analisando os atuais marcos legais da execução penal brasileira, apresenta-se a educação como um direito humano fundamental e uma importante política no tratamento penitenciário.
\end{abstract}

PALAVRAS-CHAVE: Educação de jovens e adultos. Políticas de educação. Restrição e privação de liberdade.
SUMMARY: Result of research undertaken in recent years on education for youth and adults in situations of restriction and deprivation of liberty in Brazil, the article presents some reflections on the subject, highlighting mainly the legal, political and social aspects involving the discussion. Analyzing the current legal framework of the Brazilian penal execution, presents education as a fundamental human right and an important policy in the penitentiary treatment.

KEYWORDS: Youth and adult education. Education policy. Restriction and deprivation of liberty. 
* Professor Adjunto do Instituto de Educação de Angra dos Reis e do Programa de Pós-Graduação em Educação da Universidade Federal Fluminense (UFF). Vice-coordenador do Observatório Jovem do Rio de Janeiro e do Núcleo de Estudos e Documentação em Educação de Jovens e Adultos da UFF.

1 Variam conforme cada época e cada cultura; é necessário para o conhecimento si mesmo, do mundo a qual fazemos parte, a nossa participação na vida produtiva, nas decisões coletivas, além de possibilitar que continuemos aprendendo.

2 Devem ser compreendidas como requisitos básicos para se viver e trabalhar em uma sociedade.

3 Normas, princípios ou padrões sociais aceitos ou mantidos por indivíduo, classe, sociedade etc.

\section{INTRODUÇÃO}

A Conferência Mundial sobre Educação realizada em Jomtien, na Tailândia, em 1990, definiu como conteúdos da educação: os conhecimentos ${ }^{1}$, as habilidades ${ }^{2}$, os valores $^{3} \mathrm{e}$ as atitudes.

O Conselho Econômico e Social das Nações Unidas, em sua resolução 1990/20 de 24 de maio de 1990, recomendou, entre outras coisas, que todos os reclusos deviam gozar de acesso à educação, com inclusão de programas de alfabetização, educação básica, formação profissional, atividades recreativas, religiosas e culturais, educação física e desporto, educação social, ensino superior de serviços de bibliotecas (ONU; Unesco, 1994. p. 1).

Alguns países como a Noruega (1993) e Suécia (1992) publicaram disposições legislativas que especificam a finalidade da educação em espaços de restrição e privação deliberdade como preparação para reinserção na sociedade, exigindo que nas prisões se desenvolvam atividades tanto educacionais quanto culturais e que deem à educação a mesma importância que o trabalho.

Os educadores, autoridades penitenciárias e demais pessoas nem sempre estão de acordo sobre a finalidade da educação nas prisões. Algumas autoridades penitenciárias e funcionários da área de segurança tendem a considerar os programas educacionais como uma atividade periférica, que contribui para a 'boa ordem' da instituição, já que ajuda a manter os reclusos 'proveitosamente ocupados', outros, especialmente os educadores e pessoal civil (trabalhadores sociais, sociólogos etc.), tendem a destacar os aspectos éticos da educação como parte da finalidade reabilitadora do encarceramento. Um elemento evidente deste objetivo, mas que geralmente é mantido entre palavras ou em silêncio, é o desejo de influenciar o comportamento futuro dos delinquentes mediante uma modificação dos seus valores e atitudes. Este aspecto fica implícito nos objetivos das instituições e sistemas caracterizados como 'correcionais'. (ONU; Unesco, 1994. p. 13).

A educação é considerada como um dos meios de promover a integração social e a aquisição de conhecimentos que permitam aos reclusos assegurar um futuro melhor quando recuperar a liberdade. Esta posição talvez seja compartilhada pelos apenados que compreendem que o encarceramento tem uma finalidade que vai além do castigo, da segregação e dissuasão e que, portanto, aceitam voluntariamente e aprovam o aspecto reformador do encarceramento, em especial as atividades de educação profissional e as informações sobre oportunidades de emprego. Outros apenados, ao contrário, rechaçam a educação como parte de um sistema impositivo e castrador, 
que os querem alienados. Sem dúvida alguma, por outro lado, é possível ainda que muitos apenados participem inicialmente das atividades educativas por razões alheias a educação, como, por exemplo: sair das suas celas, estar com amigos ou evitar o trabalho etc.

A educação em espaços de restrição e privação de liberdade pode ter, principalmente, três objetivos imediatos que refletem as distintas opiniões sobre a finalidade do sistema de justiça penal: (1) manter os reclusos ocupados de forma proveitosa; (2) melhorar a qualidade de vida na prisão; e (3) conseguir um resultado útil, tais como ofícios, conhecimentos, compreensão, atitudes sociais e comportamento, que perdurem além da prisão e permitam ao apenado o acesso ao emprego ou a uma capacitação superior, que, sobretudo, propicie mudanças de valores, pautando-se em princípios éticos e morais. Esta educação pode ou não se reduzir ao nível da reincidência. Já os demais objetivos formam parte de um objetivo mais amplo que a reintegração social e desenvolvimento do potencial humano.

Levando-se em consideração que o cárcere tem como objetivo central a reinserção social do apenado, deverá estar estruturado de forma que possibilite, a qualquer custo, garantir os direitos fundamentais do interno (integridade física, psicológica e moral), viabilizando a sua permanência de forma digna e capacitando-lhe para o convívio social e para o seu desenvolvimento pessoal e social.

Compreendendo a educação como o único processo capaz de transformar o potencial das pessoas em competências, capacidades e habilidades - os demais (saúde, alimentação, integridade física, psicológica e moral) são condições para a efetivação da ação educativa - e educar como o ato de criar espaços para que o educando, situado organicamente no mundo, empreenda a construção do seu ser em termos individuais e sociais, o espaço carcerário (de privação de liberdade), com todas as suas idiossincrasias, deve ser entendido como um espaço educativo, ambiente socioeducativo. Assim sendo, todos que atuam nestas unidades (dirigente, técnico e operacional) são educadores (socioeducadores) e devem, independente da sua função, estar orientados nessa condição. Todos os recursos e esforços devem convergir, com objetividade e celeridade, para o trabalho educativo. Ou seja, todas as unidades devem possuir um Projeto Político Institucional que oriente as ações, defina os recursos e viabilize uma atuação consciente e consistente com o plano individual de trabalho ${ }^{4}$ do interno.

As ações educativas devem exercer uma influência 4 A Lei de Execução Penal visando a "indi-
vidualização da pena" prevê que a Comissão Técnica de Classificação deve apresentar propostas de "Plano de Atendimento Individualizado" aos internos, levando-se em consideração a pessoa humana, suas limitações e especificidades.

ificante na vida do interno, criando condições para que molde sua identidade, buscando, principalmente, compreender-se e aceitar-se como indivíduo social, e construir seu projeto de vida, definindo e trilhando 
5 Coleção produzida pela Secretaria Especial dos Direitos Humanos sob a coordenação técnica do professor Antônio Carlos Gomes da Costa: Livro 1 (Por uma política Nacional de Execução das Medidas Socioeducativas); Livro 2 (Os Regimes de Atendimento no Estatuto da Criança e do Adolescente); Livro 3 (As Bases Éticas da Ação Socioeducativa); Livro 4 (Parâmetros para a Formação do Socioeducador); e Livro 5 (Socioeducação: Estrutura e Funcionamento da Comunidade Educativa). DF: SEDH, 2006. caminhos para a sua vida em sociedade. Assim como deve existir educação escolar e a educação profissional dentro do espaço carcerário como política de execução penal, hoje também se defende que deve existir uma proposta políticopedagógica orientada na socioeducação, cujo objetivo seja preparar o apenado para o convívio social.

Fruto de estudos realizados ao longo de uma década e meia com pesquisas na área de educação para jovens e adultos em situação de restrição e privação de liberdade e com a gestão da política de execução penal no Brasil, analisando os marcos legais e operacionais da política nas últimas décadas, este artigo tem como objetivo, em linhas gerais, ampliar as discussões sobre políticas de segurança e de privação de liberdade na sociedade contemporânea, principalmente destacando as lutas pelo reconhecimento das garantias de direitos humanos no cárcere.

Em síntese, debateremos sobre as principais questões que evidenciam a mudança de uma concepção política de restrição e privação de liberdade que ultrapassa o paradigma conservador da instituição total, defendendo, em linhas gerais, o paradigma democrático e descentralizador da incompletude institucional.

Levando em consideração diversos aspectos teóricos, políticos e pedagógicos que envolvem a política de execução penal no Brasil, o objetivo central do artigo é analisar os marcos legais atuais da execução penal brasileira, apresentando a educação como um direito humano fundamental e uma importante política no tratamento penitenciário.

\section{A EDUCAÇÃO ESCOLAR NAS PRISÕES: POR UMA POLITICA SOCIOEDUCATIVA}

Recente publicação produzida pela Secretaria Especial dos Direitos Humanos (2006) direcionada à área socioeducativa, intitulada Socioeducação: estrutura e funcionamento da comunidade educativa ${ }^{5}$, define a socioeducação como educação para socialização, o caminho do desenvolvimento pessoal e social, ou seja, preparar o indivíduo para avaliar soluções e tomar decisões corretas em cima de valores: aprender a ser e a conviver. Compreende que a educação deve garantir as seguintes competências: pessoal (relaciona-se com a capacidade de conhecer a si mesmo, compreender-se, aceitar-se, aprender a ser); social (capacidade de relacionar-se de forma harmoniosa e produtiva com outras pessoas, aprender a conviver); produtiva (aquisição de habilidades necessárias para se produzir bens e serviços, aprender a fazer); e cognitiva (adquirir os conhecimentos necessários ao seu crescimento pessoal, social e profissional, assegurar a empregabilidade e/ou a trabalhabilidade).

A socioeducação deve ter como fundamento os princípios de liberdade e os ideais de solidariedade e, como fim, a formação plena do educando, a sua preparação para o exercício 
6 Constituição Federal de 1988; LDEN de 1996; Parecer 11/2000; Resolução CNE/ CEB 1/2000 e Resolução CNE/CEB 3/2010. da cidadania e sua qualificação para o trabalho, com base na letra e no espírito do Art. $2^{\circ}$ da LDBEN: "a educação é direito de todos e dever da família e do Estado, terá como bases os princípios de liberdade e os ideais de solidariedade humana, e, como fim, a formação integral da pessoa do educando, a sua preparação para o exercício da cidadania e sua qualificação para o trabalho". (Costa, 2006, p. 23).

Conforme o Art. 83 da Lei de Execução Penal Brasileira, todo "estabelecimento penal, conforme a sua natureza, deverá contar em suas dependências com áreas e serviços destinados a dar assistência, educação, trabalho, recreação e prática esportiva".

No seu Art. 10 do Capítulo II - Da Assistência, afirma que "a assistência ao preso e ao internado é dever do Estado, objetivando prevenir o crime e orientar o retorno à convivência em sociedade”. Para tanto, será: material, à saúde, jurídica, educacional, social e religiosa.

Levando-se em consideração a complexidade das questões nas discussões sobre a Educação de Jovens e Adultos (EJA) no Brasil, principalmente pela sua perspectiva legal ${ }^{6}$, através da Lei de Execução Penal (Lei ${ }^{\circ}$ 7.210, de 11 de julho de 1984), a assistência educacional do preso é expressamente prevista como um direito no inciso VII, do artigo 41. Nos artigos 17 a 21, da EJA em espaços de privação de liberdade no país, que estabelece como a assistência educacional ao preso e ao internado se dará, compreende como instrução escolar e formação profissional determinando: (a) obrigatoriedade do ensino fundamental; (b) ensino profissional ministrado em nível de iniciação ou de aperfeiçoamento técnico; (c) adequação do ensino profissional da mulher à sua condição; (d) possibilidade de convênio com entidades públicas ou particulares, que instalem escolas ou ofereçam cursos especializados; (e) previsão de dotar cada estabelecimento com uma biblioteca para uso de todas as categorias de reclusos, provida de livros instrutivos, recreativos e didáticos.

Neste documento, observa-se certa restrição às oportunidades educacionais nos presídios se comparada à educação fornecida aos jovens e adultos que não se encontram no sistema prisional: apenas o ensino fundamental foi preceituado como obrigatório, não sendo prevista e garantida a possibilidade de acesso ao ensino médio ou superior para os detentos que cumprem pena em regime fechado, o que viola normas constitucionais que postulam como dever do estado a "progressiva universalização do ensino médio gratuito" (artigo 208, inciso II) e o "acesso aos níveis mais elevados do ensino, da pesquisa e da criação artística, segundo a capacidade de cada um" (artigo 208, inciso V).

A escola, seja para crianças, jovens e adultos, inclusive em ambientes de privação de liberdade, deve ser 
7 O Ministério da Educação, através do seu Programa "Brasil Alfabetizado", vem implementando, em parceria com as respectivas secretarias de estado de educação, uma proposta de alfabetização em diversos presídios brasileiros. Em algumas regiões, o Programa passa a ser a única proposta de educação para o interno penitenciário. concebida como um espaço de encontro e socialização ao mundo livre em que o saber é apenas um dos elementos para a sua constituição. Precisa-se romper com a concepção tradicional e reducionista de escola, cujo objetivo central está na aquisição de conteúdos pragmáticos e muitas vezes descontextualizados do ambiente em que vivemos, principalmente do mundo moderno.

O tema educação é interpretado na Lei de Execução Penal distintamente pelos diversos estados. Enquanto uns vêm investindo na implementação de ações e políticas de incentivo à educação como prática na execução penal, outros, pouco ou quase nada fazem nessa direção.

A questão da educação como programa de ressocialização na política pública de execução penal é um assunto ainda nebuloso. Reduzidas são as discussões que vêm sendo implementadas nesta direção. Poucos são os estados que vêm reconhecendo a sua importância no contexto político da prática carcerária.

Segundo Lemgruber (2004, p. 318),

[...] apenas 17,3\% dos presos estão envolvidos em alguma atividade educacional no Brasil. Levando-se em conta que $70 \%$ dos presos não terminaram o $1^{\circ}$ grau [atual ensino fundamental] e que cerca de $10 \%$ [segundo ela] são analfabetos, é óbvio que os sistemas penitenciários não parecem estar interessados em alterar tal quadro. Ademais, considerando que 83,3\% dos estados mantém convênios com as Secretarias de Educação para o desenvolvimento de atividades educacionais, o quadro resulta ainda mais absurdo.

Reconhecidamente como atividades educacionais, poucas são as experiências que vêm se consolidando ao longo dos anos no país. Vários estados possuem ações isoladas e muitas vezes não institucionalizadas. São geralmente projetos de curta duração e com atendimento reduzido7. Muitos não conseguem nem mesmo cumprir o que determina a Lei de Execução Penal, ou seja, o oferecimento do ensino de primeiro grau - atual ensino fundamental - para seus internos penitenciários.

O Estado brasileiro tem sido historicamente incompetente para prover educação e trabalho ao preso. Constroem-se unidades prisionais sem espaço para oficinas de trabalho. Constroem-se unidades prisionais sem escola. Existem escolas que não ensinam. A educação para o trabalho é absolutamente ignorada, quando existem recursos do Fundo de Amparo ao Trabalhador (FAT) que podem ser utilizados para tal finalidade. (Lemgruber, 2004, p. 336).

Cabe assinalar que a importância da educação nos presídios vem ao encontro de duas finalidades tão privilegiadas pela sociedade: coibir a ociosidade nos 
80 trabalho na prisão diminui as chances de reincidência em $48 \%$.
9 Concepção político pedagógica de execução penal que compreende o cárcere como "instituição total"/ "instituição completa", em que o indivíduo é capturado da sociedade, segregado totalmente da comunidade livre

10 Esta nova concepção compreende o sistema penitenciário com uma instituição social como tantas outras, reconhecendo a sua incompletude (tanto institucional quanto profissional). presídios, que, segundo alguns operadores da justiça e da execução penal, gera maior propensão à reincidência, e dar ao condenado a oportunidade de, em futura liberdade, dispor de uma opção para o exercício de alguma atividade profissional, para a qual seja exigido um mínimo de escolarização. Assim, a opção por tirar uma grande massa da população carcerária que está na ociosidade, colocando-a em salas de aula, não constitui privilégio - como querem alguns -, mas uma proposta que atende os interesses da própria sociedade.

Estudo realizado por Julião (2012) para a sua tese de doutoramento apresenta ainda como resultado que "o estudo no cárcere diminui a probabilidade de reincidência em 39\%". Ou seja, a educação, segundo o estudo, tem um impacto significativo na reinserção social do apenado.

Os Ministérios da Educação e da Justiça, reconhecendo a importância da educação para este público, iniciou em 2005 uma proposta de articulação nacional para implementação de Programa Nacional de Educação para o Sistema Penitenciário, formulando as suas Diretrizes Nacionais. A referida proposta, apoiada pela UNESCO, culminou em 2006, 2007, 2012 e 2013 com a realização de Seminários Nacionais de Educação para o Sistema Penitenciário.

Importantes passos foram dados no Brasil, nos últimos anos, principalmente com a aprovação das Resoluções $\mathrm{n}^{0}$ 3, de 11 de março de 2009, do Conselho Nacional de Política Criminal e Penitenciária (CNPCP), e $\mathrm{n}^{\mathrm{O}} 2$ do Conselho Nacional de Educação (CNE), de 19 de maio de 2010, que aprovam as "Diretrizes Curriculares Nacionais para Educação no Âmbito do Sistema Prisional”. Ambas garantem que a educação seja implementada pelos órgãos responsáveis pela política de educação na sociedade brasileira. Ou seja, deixa de ser um projeto implementado pelos gestores da execução penal para ser uma política de educação nacional fundamentada em princípios legais que garantem os direitos do apenado como cidadão e não simplesmente como um preso.

Em uma perspectiva que garante o direito dos apenados ao estudo no cárcere, defende uma concepção política de restrição e privação de liberdade que ultrapassa o paradigma conservador da instituição total", defendendo, em linhas gerais, o paradigma democrático e descentralizador da incompletude institucional ${ }^{10}$. Defende uma nova dinâmica política e ideológica que prima pela não segregação total do indivíduo, pela concepção de que o ser humano vive em um constante processo de socialização. Reconhece-se que o papel do sistema de privação de liberdade, em suma, é de "sócio-educar": do compromisso com a segurança da sociedade e de promover a educação do delinquente para o convívio social.

O tema educação para jovens e adultos privados de liberdade, nos últimos anos vem alcançando internacionalmente 
12 Em junho de 2006, teve lugar em Cartagena de Índias (Colômbia) o primeiro encontro de Redes Eurosocial. Nesse encontro, as propostas de intercambio foram acordadas de maneira consensual pelo conjunto dos participantes, com o objetivo de iniciar um processo reflexivo e estratégico de criação da Rede Latino-americana especializada no tema de Educação nas prisões. Em 2007 foi realizado o Encontro Internacional da Associação Europeia de Educação nas Prisões (Irlanda). Em 2014 foi realizado no Rio de Janeiro (Brasil), o Encontro Latino Americano de Educação para Jovens e Adultos em Situação de Restrição e Privação de Liberdade.

13 Infelizmente, por diversas questões, principalmente pela mudança de governo e descontinuidade administrativa tão presente na cultura política dos países Latino-Americanos, a RedLECE, desde de 2010 está totalmente parada. Não vem realizando atividades para socialização das experiências dos países integrantes. Em 2014, por iniciativa dos Programas de Pós-graduação em Educação das Universidades Federal Fluminense, Universidade Federal da Paraíba e Universidade Federal de São Carlos, foi realizado Encontro Latino Americano de Educação para Jovens e Adultos em Situação de Restrição e Privação de Liberdade com o objetivo de retomar as atividades da Rede.

14 O pesquisador nos chama atenção para o fato de que "a organização da educação na prisão reflete também as atitudes da opinião pública. Nos países em que o orçamento para a escola regular não é suficiente, fica difícil explicar por que a educação na prisão precisa de dinheiro público". Embora a educação na prisão é também um direito de todos, segundo ele, "entretanto isso não parece ser uma realidade dentro da comunidade internacional de educação, mesmo quando muitas iniciativas são tomadas nos níveis locais e internacionais". Campanhas internacionais ou regionais geralmente dão pouca ou nenhuma atenção para esse problema que envolve dezenas de milhões de pessoas no mundo (Maeyer, 2006, p. 19). um inacreditável destaque ${ }^{12}$. A partir de 2006, iniciou-se um movimento governamental na perspectiva de criação da Rede Latino-americana de Educação nas Prisões (RedLECE) ${ }^{13}$. O objetivo da rede, à luz do que vem sendo realizado sobre o tema em outras regiões do mundo, como na Europa, é investir no intercâmbio de experiências, bem como de consolidar práticas que institucionalizem uma política educativa para o sistema penitenciário da América Latina.

Durante muitos anos, ninguém dentro do sistema penitenciário se preocupou com a capacitação profissional do interno penitenciário. Hoje, embora ainda timidamente, inicia-se tal discussão. Acreditam que através da qualificação profissional dos internos se consiga inseri-los (ou reinseri-los) no mercado da força de trabalho. Diante das questões explicitadas, várias são as indagações que merecem a nossa atenção, dentre elas: qual o real papel da educação no sistema penitenciário? Como deve se efetivar uma educação para adultos privados de liberdade?

Em artigo assinado por um importante especialista sobre o tema, o pesquisador Marc de Maeyer (2006, p. 19), refletindo se na prisão existe a perspectiva da educação ao longo da vida, enfatiza:

[...] a educação na prisão tem uma porção de justificativas (explícitas) e preocupações: garantir um mínimo de ocupação para os internos (ter certeza de que a segurança e a calma estejam garantidas), oferecer mão de obra barata para o mercado de trabalho, quebrar o lado ruim da personalidade e construir um novo homem e uma nova mulher, apresentando atitudes e comportamentos religiosos, oferecer ferramentas para a vida externa, reeducar, reduzir a reincidência etc.

Criticando e refletindo sobre tal indagação, o pesquisador, recuperando os preceitos defendidos na Declaração de Hamburgo (1997), principalmente a de que "a educação é um direito de todos", independente de idade, raça, sexo, credo ou religião, afirma que educar é promover um direito, não um privilégio, que não se resume a um treinamento prático, mas sim destacar a dimensão social, profissional e cultural da cidadania ${ }^{14}$.

Defende uma educação global, pois, segundo ele, "recolhe pedaços dispersos da vida; dá significado ao passado; dá ferramenta para se formular um projeto individual ao organizar sessões educacionais sobre saúde, direitos e deveres, não-violência, auto-respeito, igualdade de gênero" (Maeyer, 2006, p. 35). Nesse sentido, ela não será só formal ou informal, ministrada por professores e técnicos da área de educação, mas sim se constituirá de encontros, reuniões, debates, leituras, atitudes etc, bem como será de responsabilidade dos 
15 É importante que compreendamos o "espaço de privação de liberdade" como um ambiente socioeducador. Nesse sentido, todos os profissionais dos sistemas de privação de liberdade (sistema penitenciário e o socioeducativo) são socioeducadores. agentes penitenciários, dos assistentes sociais, psicólogos, médicos e enfermeiros ${ }^{15}$.

Compreendida em uma concepção macro, devemos defender que "a educação na prisão não é apenas ensino, mesmo que devamos ter certeza de que a aprendizagem de conhecimentos básicos esteja assegurada. [...] a educação deve ser, sobretudo: desconstrução/reconstrução de ações e comportamentos" (Maeyer, 2006, p. 22).

\section{CONSIDERAÇÕES FINAIS}

O tema educação, qualificação profissional e trabalho como proposta de inclusão social para detentos e egressos do sistema penitenciário, ainda pouco explorado pelos estudiosos, está a exigir pesquisas e reflexões, mormente no que se refere às alternativas de educação para qualificar um contingente de pessoas tão heterogêneo, tanto do ponto de vista sociocultural quanto educacional. É com a certeza da maior relevância da discussão que se evidencia a carência de investigação sobre o assunto.

É importante destacar que, apesar do aspecto educacional constar na Lei de Execução Penal (LEP), no Código Penal e no Código de Processo Penal, estando em sintonia com as medidas necessárias para a promoção dos direitos da pessoa humana, na realidade do sistema penitenciário esses aspectos não são ainda plenamente aplicados. A educação, embora seja tema em todos discursos políticos, nesse ambiente ocupa um papel secundário, como no resto dos investimentos públicos.

Além disso, nos artigos da LEP é possível identificar uma forte valorização do trabalho em detrimento ao direito à educação: 0 artigo 126 assegura a remição penal através do trabalho, mas não garante à educação o mesmo benefício. Essa valorização do trabalho frente a educação, além de não incentivar a procura por escolarização, reforça a sua descaracterização como um direito, colocando a educação formal como um privilégio, um plus concedido aos detentos. Por outro lado, contraditoriamente, a ausência de remição pela educação também pode ser interpretada, como reconhecimento da educação como direito, assim como a assistência médica, a jurídica, a psicológica e a social; portanto, não oferecida como moeda de troca para o interno, possibilitando-lhe a aceleração da sua liberdade. Nesse sentido, em outras palavras, o fato (da não remição) não nega necessariamente o seu caráter de direito, já que também não existe remição para as demais assistências.

O simples fato apresentado pela LEP de não reconhecimento da remição pela educação demonstra, em linhas gerais, a sua não valorização. Não que se deva concordar que a não remição pela educação garanta e/ ou represente a sua desvalorização, mas a sua ausência se apresenta como importante elemento de distinção. No momento em que se bonifica por se fazer algo, sem 
16 Metáfora utilizada pelo Diretor do Departamento Penitenciário Nacional em discurso de aberturado curso de formação de agentes penitenciários para as Penitenciárias Nacionais, na Academia de Polícia Federal. sombra de dúvida, está de alguma forma incentivando a sua realização. Ao contrário, quando não o faz, não se está privilegiando, ou, pelo menos, não se está incentivando.

Após anos de tramitação de Projetos de Lei no Congresso Nacional sobre a remição pela educação na política de execução penal, foi aprovada, em 2011, a Lei $n^{\circ}$ 12.433, que garante a Remição da pena também por estudo. A Lei garante o direito à redução de um dia na pena a cada três dias de frequência escolar no ensino fundamental, médio, profissionalizante, superior ou de requalificação profissional.

Outro fato também muito esclarecedor, é que na própria arquitetura prisional, geralmente não é previsto e não existe espaço para o desenvolvimento de atividades educativas nas unidades prisionais. Enquanto atualmente se discute a necessidade de criação de espaços para atividades laborativas no cárcere, espaços para a educação, artes e esporte não são considerados artigos de primeira necessidade, mas sim "artigos de perfumaria"16. São geralmente totalmente desconsiderados em uma política de execução penal, literalmente colocados em segundo plano. Poucas unidades, na sua concepção, previram espaços para sua realização. Atualmente, investe-se na criação de unidades industriais com tecnologias muito semelhantes às encontradas em uma realidade fabril extramuros. Porém, em outras, com poucas exceções, evidencia-se na sua infraestrutura espaços adequados que privilegiem atividades além do trabalho. São espaços improvisados, muitas vezes em estados precários de conservação e de concepção.

Embora tenha sido aprovada as Diretrizes Básicas para Arquitetura Penal (Resolução CNPCP no 9, de 18 de novembro fr 2011), evidencia-se que muitas das novas unidades que estão sendo construídas, inclusive com recursos federais, estão desrespeitando o previsto nesta Resolução. Espaços para as escolas e para os atendimentos previstos no "tratamento penitenciário" continuam sendo esquecidos na sua infraestrutura.

O Ministério da Justiça vem aprovando constantemente recursos para construção de novas unidades, inclusive para as unidades federais, sem sequer estabelecer critérios mínimos, pautando-se na Lei de Execução Penal, que definam a construção de unidades. Cada estado tem construído as suas unidades, muitas vezes sem princípios claros e definidos, contrariando geralmente a própria legislação a qual, a princípio e em tese, deveria defender.

A valorização do direito ao trabalho frente a educação traz também como consequência um maior estímulo à educação como mecanismo de acesso e preparo para o mercado de trabalho, como já explicitado anteriormente, em detrimento de outros objetivos do 
17 O problema também é evidenciado na área socioeducativa: existe um enorme desinteresse dos jovens pela escola nas unidades socioeducativas. direito à educação, como desenvolvimento pessoal ou a formação para a cidadania.

A Lei de Execução Penal também exige que todos os condenados exerçam algum tipo de trabalho, bem como que os presos tenham acesso ao ensino fundamental garantido. Mas, segundo dados do próprio Ministério da Justiça (2012), apenas $23,95 \%$ participam de alguma atividade laborativa e $17,3 \%$ estudam (efetivamente participam de atividades educacionais de alfabetização, ensino fundamental, médio e supletivo). São esses dados tão significativos que sugerem a reavaliação da atual cultura da prisão, ou seja, da proposta política de execução penal ora em vigor, pois demonstram um total descompasso com o discurso predominante, que eleva a educação e o trabalho como importantes programas de reinserção social na política pública de execução penal.

É importante ainda salientar que não quer dizer que o Estado ofereça vagas para todos àqueles que desejam estudar e trabalhar. Pelo contrário, é comum, principalmente quanto ao trabalho, ter um número muito superior de internos interessados, e poucas vagas disponíveis, principalmente quando remuneradas, transformando-se em importante moeda dentro do espaço carcerário. Por outro lado, quanto à educação, também não é muito diferente, em alguns estados se evidencia o contrário, um número imenso de vagas ociosas nas escolas, demonstrando um total desinteresse por parte dos internos em estudar.

Tal fato chama atenção de especialistas e gestores na área de educação ${ }^{17}$, pois evidencia importantes questões que merecem reflexão, dentre elas destacam-se: (1) quais os motivos que levam o apenado a (não) se interessar pela escola; (2) qual a escola ideal para o sistema penitenciário; e (3) qual o papel da educação na política de execução penal.

Embora já tenha sido aprovada as Diretrizes Nacionais para a política de educação em espaço de privação de liberdade, infelizmente, por não terem investido na implementação de um Plano Nacional com desdobramento em planos estaduais de educação para o cárcere, cada estado ainda vem apresentando propostas diversas para a implementação das suas ações. Muitos, sequer possuem uma política regulamentada para estas ações no cárcere, evidenciando-se, em várias unidades, projetos isolados, sem fundamentação teórico-metodológica, sem qualquer continuidade administrativa, beirando o total improviso de espaço, gestão, material didático e atendimento profissional.

Nessa direção, ainda destacamos, a escola intramuros, assim como a extramuros, para a população no mundo livre está em crise. Cotidianamente divulgam-se um crescente número de reprovações e evasões, detectando-se diversos problemas: (1) a escola não atende os interesses de sua 
clientela; (2) as escolas não acompanham os avanços tecnológicos e sociais da atualidade; (3) os profissionais da área de educação estão desmotivados e, consequentemente, desatualizados em relação aos conteúdos e metodologias; (4) os jovens e adultos não veem perspectivas sociais através da escola etc.

Dentro desse contexto, em suma, não adianta simplesmente replicar uma ideia de escola atualmente criticada e falida para o sistema penitenciário sem levar em consideração todos os elementos que identificam e caracterizam a privação de liberdade; que compreenda as reais necessidades do sujeito privado de liberdade; que esteja alinhada à política pedagógica de execução penal, principalmente a voltada para a garantia de direitos e de valorização à reinserção social.

Não se pode ainda deixar de destacar que também é necessário que se compreenda que esta escola está em um contexto real de política de execução penal, em que, em detrimento de uma política de reinserção social, valoriza-se uma política de coerção e custódia; em detrimento da garantia dos direitos humanos, valoriza-se, a qualquer custo, a segurança.

Como um dos possíveis encaminhamentos, acreditase que somente através da institucionalização nacional de uma política de educação para o sistema penitenciário, principalmente privilegiando as ações educacionais em uma proposta política pedagógica de execução penal como programa de reinserção social, é se conseguirá efetivamente mudar a atual cultura da prisão.

O Brasil vem vivenciando importantes momentos na implementação das suas políticas de restrição e privação de liberdade. No campo da execução penal, foram aprovadas:

(1) "Diretrizes Nacionais para a oferta de educação nos estabelecimentos penais" através da Resolução $\mathrm{n}^{0} 3$, de 11 de março de 2009, do Conselho Nacional de Política Criminal e Penitenciária;

(2) "Diretrizes Nacionais para a oferta de educação para jovens e adultos em situação de privação de liberdade nos estabelecimentos penais" pelo Conselho Nacional de Educação, através da sua Resolução $\mathrm{n}^{0}$ 2, de 19 de maio de 2010;

(3) Diretrizes Básicas para Arquitetura Penal (Resolução CNPCP n ${ }^{0}$ 9, de 18 novembro de 2011);

(4) Lei $\mathrm{n}^{0}$ 12.433/2011 (Remição da pena por estudo), que busca estimular presos a estudarem durante o cumprimento da pena, garantindo o direito à redução de um dia na pena a cada três dias de frequência escolar no ensino fundamental, médio, profissionalizante, superior ou de requalificação profissional; 
18 Como a Secretaria Especial de Políticas para as Mulheres da Presidência da República, o Departamento Penitenciário Nacional do Ministério da Justiça, a Secretaria Especial de Promoção da Igualdade Racial, Secretaria Especial dos Direitos Humanos, Ministério do Desenvolvimento Social e Combate à Fome, Ministério da Cultura, Ministério dos Esportes, Secretaria Antidrogas do Gabinete de Segurança Institucional da Presidência da República e a Secretaria Nacional da Juventude da Secretaria Nacional da Presidência da República
(5) Decreto 7.626/2011 (Plano Estratégico de Educação no âmbito do Sistema Prisional), que busca a ampliação da oferta de ensino nas unidades prisionais, na esteira da lei que cria incentivos para que condenados se dediquem aos estudos durante o cumprimento da pena;

(6) Decreto $n^{0} 7.626 / 2011$ (Plano Estratégico de Educação no âmbito do Sistema Prisional), que busca a ampliação da oferta de ensino nas unidades prisionais, na esteira da lei que cria incentivos para que condenados se dediquem aos estudos durante $o$ cumprimento da pena;

(7) Decreto Presidencial $\mathrm{s} / \mathrm{n}^{\circ}$, de 2007 , que cria o Grupo de Trabalho Interministerial - GTI composto por órgãos do governo federal ${ }^{18} \mathrm{com}$ a finalidade de "elaborar propostas para a reorganização e reformulação do Sistema Prisional feminino";

(8) Em 2012, o Ministério da Justiça, através do Departamento de Execução Penal (DEPEN), lançou o "Plano Diretor de Execução Penal", dando ênfase ao projeto estratégico para as mulheres denominado "Efetivação dos Direitos das Mulheres do Sistema Penal”. Através da Portaria ${ }^{\circ}$ 154, de 13 de abril de 2012, foi instituída a Comissão Especial, no âmbito do DEPEN, por meio da Diretoria de Políticas Penitenciárias, para a elaboração de propostas de ações para o referido projeto;

(9) Aprovação da Lei $\mathrm{n}^{\circ} 12.852$, de 5 de agosto de 2013, que institui o Estatuto da Juventude. O texto define princípios e diretrizes para o Poder Público criar e organizar políticas para cidadãos de 15 a 29 anos de idade.

Tramita ainda no Congresso Nacional o Projeto de Lei (PL 2.785/2001), enviado pelo Poder Executivo ao Congresso Nacional, que garante a Convivência familiar no sistema prisional, com o objetivo de assegurar o direito da criança e do adolescente a visitar os pais encarcerados, além de estabelecer procedimento para garantir o acesso à justiça e o devido processo legal à pessoa presa para a manutenção de laços familiares.

Em linhas gerais, podemos afirmar que o Brasil já ultrapassou a etapa que discute o direito à educação dentro do cárcere, e está agora no estágio em que deve analisar as suas práticas e experiências, procurando instituir programas, consolidar propostas e políticas, enfim, que efetivamente avalie os seus resultados. Precisamos, por exemplo, hoje investir na discussão que analisa se a escola é do ou está no sistema de penitenciário ou socioeducativo.

\section{REFERÊNCIAS}

BITTAR, Walter. Criminologia no Século XXI. Rio de Janeiro: Lumen Juris; IBCCRIM, 2007. 
BRASIL. Constituição (1988). Constituição da República Federativa do Brasil: promulgada em 5 de outubro de 1988. Organização do texto: Juarez de Oliveira. 21. ed. São Paulo: Saraiva, 1990. (Série Legislação Brasileira).

BRASIL. Código de Processo Penal. Diário Oficial da União. Rio de Janeiro, 13 out. 1941. Disponível em: http:// www.planalto.gov.br/ccivil_03/decreto-lei/Del3689.htm. Acesso: mar. 2008.

BRASIL. MINISTÉRIO DA JUSTIÇA/ Secretaria Nacional de Justiça. Seminário British-Brazizlian Law Week: Novas Tendências e Perspectivas do Direito - 1988. Distrito Federal: MJ/SNJ, 1999.

BRASIL. MINISTÉRIO DA JUSTIÇA/Departamento Penitenciário Nacional (Brasil). Síntese das Ações do Departamento Penitenciário Nacional: ano 2007 e Metas para 2008. Distrito Federal: DEPEN, 2008.

- Guia de referência para a gestão da educação em serviços penais. Distrito Federal: DEPEN, 2008.

- Matriz Curricular Nacional para a Educação em Serviços Penitenciários. Distrito Federal: DEPEN, 2008.

BRASIL. CNPCP. Conselho Nacional de Política Criminal e Penitenciária. Resolução 14, de 11 nov. 1994. Regras Mínimas para o Tratamento do Preso no Brasil. Diário Oficial da União. Brasília: CNPCP, 1995.

BRASIL. Ministério da Justiça. Regras de Tóquio: comentários às Regras Mínimas das Nações Unidas sobre as Medidas de Não-Privativas de Liberdade. Brasília: Ministério da Justiça, 1998.

BRAUN, Helenice. Brasil e os Direitos Humanos: a incorporação dos tratados em questão. Ijuí: Unijuí, 2002.

BREITMAN, Miriam. I. Rodrigues. Mulheres, crimes e prisão: o significado da ação pedagógica em uma instituição carcerária feminina. Dissertação (Mestrado em Educação) - Faculdade de Educação, Universidade Federal do Rio Grande do Sul. Porto Alegre, 1989.

CARVALHO, José Murilo de. Cidadania no Brasil: o longo caminho. Rio de Janeiro: Civilização Brasileira, 2001.

CHIES, Luiz Antônio Bogo. Prisão e Estado: a função ideológica da privação de liberdade. Pelotas: Educat, 1997.

COSTA, Antônio Carlos G. Socioeducação: Estrutura e funcionamento da comunidade educativa. Brasília: Secretaria Especial de Direitos Humanos, 2006a. 
COSTA, Antônio Carlos G. Por uma política nacional de execução das medidas socioeducativas: conceitos e princípios norteadores. Brasília: Secretaria Especial de Direitos Humanos, 2006b.

Parâmetros para a formação do socioeducador: uma proposta inicial para reflexão e debate. Brasília: Secretaria Especial de Direitos Humanos, 2006c.

Os regimes de atendimento no Estatuto da Criança e do Adolescente: Perspectivas e desafios. Brasília: Secretaria Especial de Direitos Humanos, 2006d.

As bases éticas da ação socioeducativa: referenciais normativos e princípios norteadores. Brasília: Secretaria Especial de Direitos Humanos, 2006e.

COYLE, Andrew. Administração penitenciária: uma abordagem de Direitos Humanos - Manual para servidores penitenciários. Londres: Internacional Centre for Prison Studies, 2002.

JULIÃO, Elionaldo Fernandes. Educação para jovens e adultos para situação de restrição e privação de liberdade: questões, avanços e perspectivas. Jundiaí: Paco Editorial, 2013.

Sistema Penitenciário Brasileiro: $A$ educação e o trabalho na Política de Execução Penal. Rio de Janeiro:DP et ali \& Faperj, 2012.

LEMGRUBER, Julita. Arquitetura Institucional do Sistema Único de Segurança Pública: Acordo de Cooperação Técnica. Distrito Federal: Ministério da Justiça, Secretaria Nacional de Segurança Pública, Federação das Indústrias do Rio de Janeiro, Serviço Social da Indústria e Programa das Nações Unidas para o Desenvolvimento, 2004.

MAEYER, Marc. Na prisão existe a perspectiva da educação ao longo da vida? Alfabetização e Cidadania: Revista de Educação de Jovens e Adultos. Brasília: Raaab, Unesco, Governo Japonês, 2006.

MORAES, Pedro R. Bodê. Retórica e a prática da ressocialização em Instituições Prisionais. Curitiba: Grupo de Estudos da Violência (UFPR), 2001.

ONOFRE, Elenice Maria C. (Org.). Educação escolar entre as grades. São Carlos: EDUFSCAR, 2007.

ONU; UNESCO. La Educación Básica en los Establecimientos Penitenciarios. EUA; Viena: Unesco; ONU, 1994.

PAIVA, Jane. Sentidos do Direito à Educação para Jovens e Adultos. Petrópolis: DP et Alii; Rio de Janeiro: Faperj, 2009. 
THOMPSON, Augusto. Questão da penitenciária. 2. ed. Rio de Janeiro: Forense, 1980.

UNESCO, Observatório Internacional De Educação nas Prisões. Na vida estamos em constante aprendizagem, mesmo não querendo aprender. Bélgica: Unesco, 2005.

.LaEducación BásicaenlosEstablecimientos Penitenciarios. Hamburgo: Unesco; ONU, 1994.

. Educación en prisiones en Latinoamérica: derechos, libertad y ciudadanía. Brasília: Unesco, 2008.

WACQUANT, Loïc. Prisões da Miséria. Rio de Janeiro: Jorge Zahar, 2001. 